\title{
Evaluation of microstructure of A356 aluminum alloy casting prepared under vibratory conditions during the solidification
}

\author{
SAKENDRA KUMAR and S P TEWARI* \\ Mechanical Engineering Department, Indian Institute of Technology (BHU), Varanasi 221005, India \\ e-mail: skumar.rs.mec12@itbhu.ac.in; sptewari.mec@itbhu.ac.in
}

MS received 5 October 2015; revised 21 March 2016; accepted 2 May 2016

\begin{abstract}
The objective of this investigation was to evaluate the effect of vibrations (during solidification) on the metallurgical properties of A356 aluminum casting. Mechanical vibrations were applied to A356 aluminum alloy through set up. A356 melt has been subjected to mechanical vibration with the frequency range from 0 to $400 \mathrm{~Hz}$ with constant amplitude $5 \mu \mathrm{m}$. Grain refinement was obtained through mold vibration. Metallurgical properties were examined through optical microstructure, tensile fracture scanning electron microscope (SEM) and SEM image of test specimens prepared under different conditions of solidification. Results indicate that mold vibration effectively modified the microstructure of A356 casting and it has uniform and smaller grain size with fibrous silicon particle than nonvibrated casting. Grain refinement results increase in mechanical properties with increase in frequency of vibration of mold during the solidification. SEM micrograph of tensile fracture surface was carried out to study the influence of microstructure on fracture mode. SEM image of tensile fractured surface shows transgranular cleavage facets due to fracture of primary silicon particles. Fractures are brittle in nature so observation indicates low ductility and brittle fracture.
\end{abstract}

Keywords. Mechanical vibration; microstructure; grain refinement; solidification.

\section{Introduction}

A356 aluminum alloy is one of the widely used casting aluminum alloys because of its good mechanical properties such as ductility, hardness, fatigue strength, pressure tightness, melt fluidity, and machinability [1]. The microstructure gives useful information on the quality of the cast. After every melt treatment the microstructure can be investigated to assess the treatment effect. Fine and equiaxed grains are believed to be more appropriate in castings. The size and shape of eutectic silicon phase has a major role in the variation in the mechanical properties of A356 alloy [2]. Fine structures raise strength and ductility [3]. Grain refining is a common practice to ameliorate the mechanical properties of casting parts. Fine equiaxed grains in the castings improve feeding ability, uniform distribution of second phases and micro porosity, and uniformity of properties and machinability [4]. As mentioned above, some researchers investigated the size of dendritic silicon phase and the others investigated the size of primary $\alpha$ phase in A356 aluminum alloy treated by different methods. Vibration activates oscillation at different points of molten metal and generates extensive nucleation sites. According to Clausius-Clapeyron's equation, localized pressure rise due to vibration can raise the melting point

*For correspondence instantaneously. This phenomenon makes a great under cooling, and also breaks dendrite arms. The broken arms act as good nuclei themselves since their compositions are homogeneous and have a high wettability with the melt. [5] explained the grain refinement in melts under turbulence, who investigated conditions for severe turbulence in the melt. In other words, effective nucleation rate is greater in the melts under turbulence.

Abu-Dheir et al [6] studied the silicon morphology modification in the eutectic Al-Si alloy under mechanical mold vibration. They found that with the increase of the vibration amplitude the lamellar spacing tends to reduce and silicon morphology becomes more fibrous as compared to gravity casting. However, it is also reported that by exceeding a critical value of vibration amplitude, the silicon tends to coarsen.

Zhang et al [7] observed the effect of electromagnetic vibration of mould core region on the solidification structure of magnesium alloy. The experimental results showed that the electromagnetic vibration of mould-core region can significantly refine the solidification structures. It was also observed that the average grain size of AZ80 alloys in the mould core region initially decreased and then increased with the increase in electromagnetic vibration frequency, current intensities and treatment time.

Chirita et al [8] compared the influence of vibration on the solidification behavior and tensile properties of an $\mathrm{Al}-$ 
$18 \mathrm{wt} \% \mathrm{Si}$ alloy gravity castings to that of stationary solidified castings. They found that the tensile strength was improved at low vibration frequencies but decreased for high frequencies.

Vives [9] observed the effect of the vibration, which mainly originates inside the electromagnetic skin depth area and owing to the medium elasticity, is propagated throughout the melt. He experimentally found that as the magnetic field strength and amplitude of the vibrating electromagnetic pressure is very small and so cavitation effects are also small.

Wang et al [10] studied about the crystal nucleation and detachment from a chilling metal surface with vibration and concluded that the exerting vibration to a chilling solid surface is an effective way to produce lots of nuclei for forming equiaxed grains microstructure by preventing the solidifying shell to form and promoting dendrites to break off and shower down not only from the free liquid surface but also from the chilling solid surface. To obtain finer equiaxed grains, it is necessary to increase synchronously vibration frequency as well as amplitude.

Kissling and Wallace [11] reported that the vibration of a copper alloy $(\mathrm{Cu}-32 \mathrm{Zn}-2 \mathrm{~Pb}-1 \mathrm{Sn})$ improved yield and tensile strengths by about $15 \%$, with a $10 \%$ reduction in grain size from the unvibrated state. In general, the $\alpha$ copper-zinc alloys $(<35 \% \mathrm{Zn})$ exhibit grain size reduction and greater improvement in properties, while the $\alpha-\beta$ alloys do not.

Piwonka [12] reported that the vibration is the principal cause and that during solidification a zone of low-melting liquid exists immediately adjacent to the main crystal growth. Nucleation can occur, and if disturbed by vibration, banding results. This theory further states that growth takes place from these new nuclei in such a manner as to form a sandwich of liquid metal surrounded by solid metal, which is isolated from the liquid bath at the bore.

\section{Experimental programme}

In this study, commercial A356 Aluminum alloy was used. The developed experimental setup consists of a hollow rectangular base plate, a tilt plate and oscillatory table made of mild steel plates. Oscillatory table rests on two shafts which are mounted on four bearings fixed over the base plate. A356 Aluminum alloys melted in a graphite crucible in pit furnace. As soon as the molten metal reaches approximate temperature of $750^{\circ} \mathrm{C}$, it is taken out and degassed using the required quantity of degassing powder of Hexa Chloro Ethane in order to remove the dissolved hydrogen gas. Aluminum alloys will absorb or dissolve harmful quantities of hydrogen from atmosphere during melting and pouring. If the molten metal reaches the approximate pouring temperature $\left(700^{\circ} \mathrm{C}\right)$, subsequent cooling and solidification will result in gas evolution,

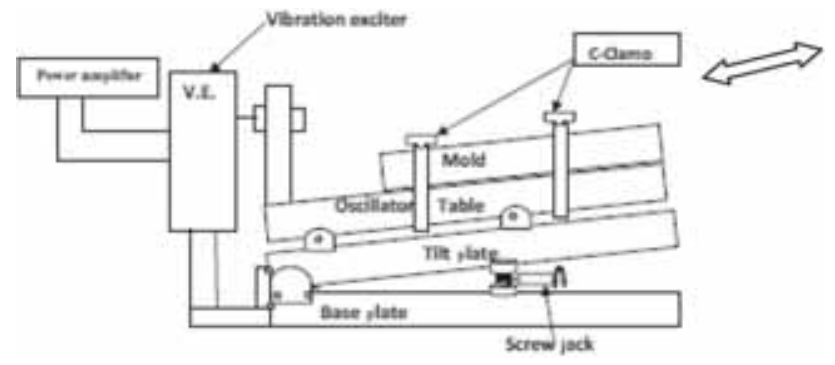

Figure 1. The experimental setup of the vibratory casting.

pinholes, and microscopic gas porosity. So degassing is performed to minimize these defects. The presence of oxides and coal ash in the surface of the molten metal are skimmed. Then the molten metal is poured into the mould cavity at a temperature of $700^{\circ} \mathrm{C}$. During the solidification of casting mold were oscillated at different frequencies $(0$ $\mathrm{Hz}, 100 \mathrm{~Hz}, 200 \mathrm{~Hz}, 300 \mathrm{~Hz}$ and $400 \mathrm{~Hz}$ ) at fixed amplitudes of vibration $5 \mu \mathrm{m}$ with the help of an oscillator/power amplifier and vibrator exciter. A circular protector was used for measurement of tilt angle. Tilt angle was provided by screw jack. The experimental setup of the vibration casting is schematically shown in figure 1 . The mild steel square mold of dimensions $16 \mathrm{~cm} \times 16 \mathrm{~cm} \times 4 \mathrm{~cm}$ with thickness $1 \mathrm{~cm}$ was directly placed on oscillatory table and was held by C-Clamps. The bar with arrows at the extremes indicates the direction of motion of the mold during vibration. The vibrator (exciter), vibration pick up and power amplifier were used in the experimentation. Thus, the vibration conditions such as frequency and amplitude could be easily controlled by oscillator/power amplifier and vibrator exciter. The vibration conditions used in this test are given in table 1 .

\section{Results and discussion}

A356 aluminum alloy casting were made without vibration to compare the results of castings with vibration during the solidification. Mechanical vibration can collapse dendrite arms during solidification and disperse them in the melt. Dispersed broken dendrite arms act as nuclei in the melt and produce finer grains and microstructure. Vibration led to the breakage of dendrite arms and dispersed them in the melt leading to grain refinement.

The ultimate tensile strength, yield strength, percentage elongation and toughness increase with increase in frequency up to $400 \mathrm{~Hz}$. Beyond $400 \mathrm{~Hz}$ the improvement in properties is insignificant for the range of values used. The results indicate that UTS and YS are about $36.7 \%$ and $21.5 \%$ respectively higher than stationary casting. The \%elongation and impact energy are 2 and 2.8 times more than stationary casting respectively. It is indicated in figure 7(a), (b). 
Table 1. The vibration conditions used for experiment.

\begin{tabular}{|c|c|c|c|c|c|}
\hline S. no. & $\begin{array}{c}\text { Mould temperature } \\
\text { (approximate pre heat) }\left({ }^{\circ} \mathrm{C}\right)\end{array}$ & $\begin{array}{l}\text { Pouring temperature } \\
\text { (approximate) }\left({ }^{\circ} \mathrm{C}\right)\end{array}$ & $\begin{array}{l}\text { Vibration } \\
\text { frequency }(\mathrm{Hz})\end{array}$ & $\begin{array}{l}\text { Amplitudes } \\
(\mu \mathrm{m})\end{array}$ & $\begin{array}{l}\text { Remark degassing with } 5 \mathrm{gm} / \mathrm{kg} \\
\text { hexachloro ethane }\end{array}$ \\
\hline 1 & 165 & 700 & 0 & 0 & \\
\hline 2 & 165 & 700 & 100 & 5 & ", \\
\hline 3 & 165 & 700 & 200 & 5 & " \\
\hline 4 & 165 & 700 & 300 & 5 & ' \\
\hline 5 & 165 & 700 & 400 & 5 & ', \\
\hline
\end{tabular}

The elemental characterization of casting was studied using SEM coupled with energy dispersive X-ray spectroscopy (EDS) software. The aim was to understand the element composition (weight\%) and corresponding EDS spectrum present at area of interest represented in figures 2(a)-(c). In the examined surface $\mathrm{Al}-\mathrm{K}, \mathrm{Si}-\mathrm{K}, \mathrm{Mg}-\mathrm{K}$, $\mathrm{Fe}-\mathrm{K}, \mathrm{Ti}-\mathrm{K}, \mathrm{Mn}-\mathrm{L}, \mathrm{Fe}-\mathrm{L} \mathrm{Ni}-\mathrm{L}, \mathrm{Cu}-\mathrm{L}$ and $\mathrm{Zn}-\mathrm{L}$ elements are found along with $\mathrm{O}$, which indicates the possible formation of oxides such as $\mathrm{SiO}_{2}, \mathrm{MgO}$ and $\mathrm{Al}_{2} \mathrm{O}_{3}$ as shown in figure 2(c). The same is also confirmed from EDS elemental mapping of these elements distribution such as $\mathrm{Al}-\mathrm{K}_{\mathrm{a} 1}, \mathrm{Si}-\mathrm{K}_{\mathrm{a} 1}, \mathrm{Zn}-\mathrm{L}_{\mathrm{a} 12}, \mathrm{Cu}-\mathrm{L}_{\mathrm{a} 12}, \mathrm{Ni}-\mathrm{K}_{\mathrm{a} 1}, \mathrm{Mn}-\mathrm{K}_{\mathrm{a} 1}, \mathrm{Mg}-$ $\mathrm{K}_{\mathrm{a} 12}$, and $\mathrm{Ti}-\mathrm{K}_{\mathrm{a} 1}$ also confirms in intermetallic presence in the scanned microstructure indicated in figure 2(d).

The micrographs obtained with A356 cast alloys under stationary and vibratory condition are shown in figure 3(b) and figure 4(a-d). Micrographs conditions alloys show $\mathrm{Al}$ dendrites, fine eutectic mixture, and $\mathrm{Si}$ particles in the non-dendritic region and inter dendritic region. Castings were solidified under stationary and vibratory condition.
EDS mapping images:

(a)

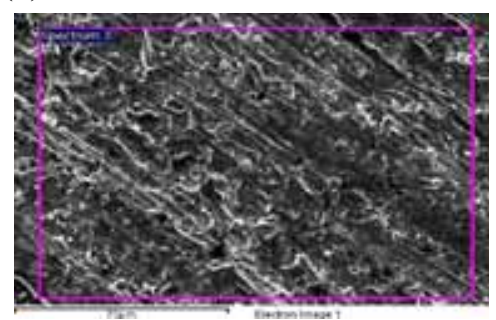

(c)

\begin{tabular}{|c|c|c|}
\hline Element & Weight $\%$ & Atomic\% \\
\hline $\mathrm{OK}$ & 3.52 & 2.03 \\
\hline $\mathrm{Mg} \mathrm{K}$ & 0.32 & 0.32 \\
\hline $\mathrm{Al} \mathrm{K}$ & 86.36 & 85.35 \\
\hline Si K & 7.57 & 7.86 \\
\hline Ti K & 0.26 & 0.15 \\
\hline $\mathrm{Mn} \mathrm{L}$ & 0.36 & 0.74 \\
\hline $\mathrm{Fe} \mathrm{L}$ & 0.6 & 1.73 \\
\hline $\mathrm{Ni} \mathrm{L}$ & 0.31 & 0.54 \\
\hline $\mathrm{Cu} \mathrm{L}$ & 0.47 & 0.83 \\
\hline $\mathrm{Zn} \mathrm{L}$ & 0.23 & 0.45 \\
\hline Totals & 100.00 & \\
\hline
\end{tabular}

(b)

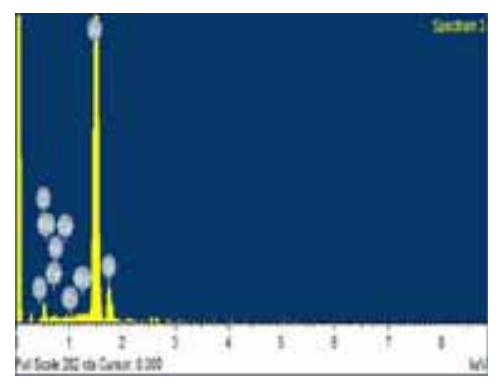

(d)

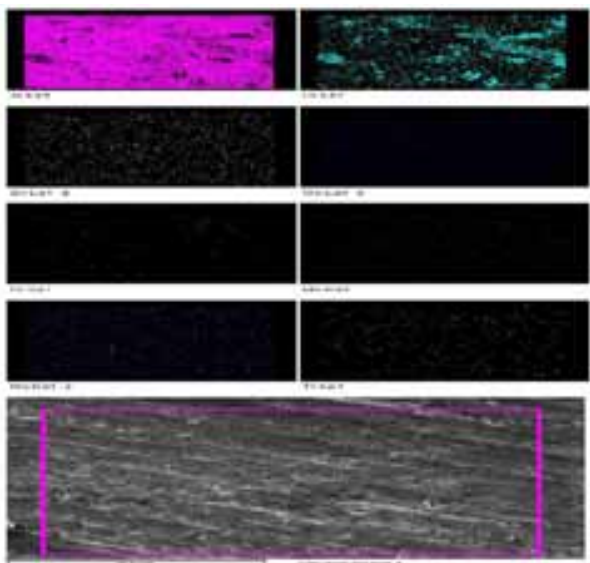

Figure 2. EDS spectrum and element distribution from EDS mapping of A 356. (a) Processing option: All elements analyzed (normalized). (b) EDS Spectrum. (c) Element composition (weight\% and atomic\%). (d) EDS elemental mapping. 

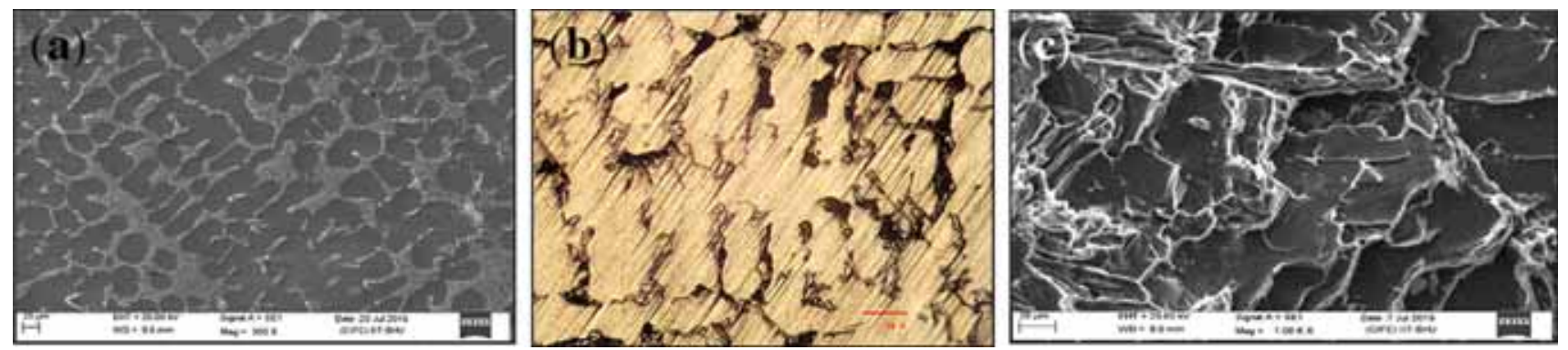

Figure 3. Image of specimen at amplitude $=0 \mu \mathrm{m}$ and frequency $=0 \mathrm{~Hz}$. (a) SEM image of surface. (b) Optical micrographs. (c) SEM image of tensile fracture.
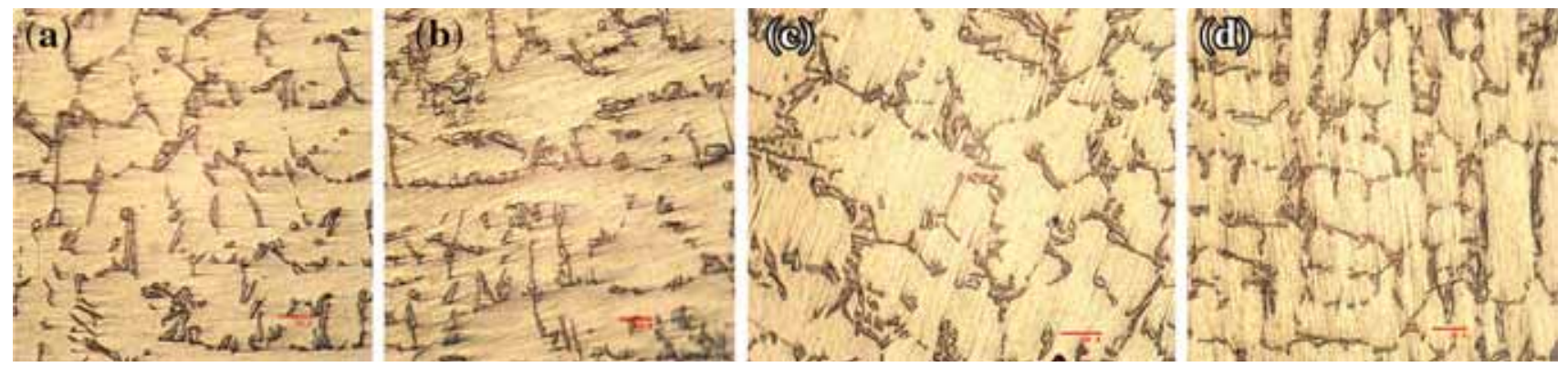

Figure 4. Optical micrographs showing eutectic silicon particle modified through mechanical vibration at amplitude $=5 \mu \mathrm{m}$ and frequency = 100-400 Hz. (a) $100 \mathrm{~Hz}$, (b) $200 \mathrm{~Hz}$, (c) $200 \mathrm{~Hz}$, and (d) $400 \mathrm{~Hz}$.

Table 2. Characterization of eutectic silicon particle and grain size at different frequencies of vibration during the solidification of A356 aluminum alloy casting.

\begin{tabular}{|c|c|c|c|c|c|c|}
\hline \multirow[b]{2}{*}{ Frequency } & \multirow[b]{2}{*}{ Grain size $(\mu \mathrm{m})$} & \multicolumn{2}{|c|}{ Silicon particle size $(\mu \mathrm{m})$} & \multirow[b]{2}{*}{ Area $\left(\mu \mathrm{m}^{2}\right)$} & \multirow[b]{2}{*}{ Asp. ratio } & \multirow[b]{2}{*}{ Roundness $(\%$} \\
\hline & & Length $(\mu \mathrm{m})$ & Width $(\mu \mathrm{m})$ & & & \\
\hline 0 & 49.19 & 17.45 & 13.23 & 1318.47 & 1.47 & 33.66 \\
\hline 100 & 42.79 & 11.86 & 7.16 & 469.07 & 1.65 & 52.76 \\
\hline 200 & 36.15 & 12.08 & 5.8 & 385.61 & 2.17 & 60.39 \\
\hline 300 & 29.13 & 10.02 & 4.5 & 231.98 & 2.22 & 67.42 \\
\hline 400 & 20.53 & 6.23 & 3.14 & 186.18 & 2.23 & 71.57 \\
\hline
\end{tabular}
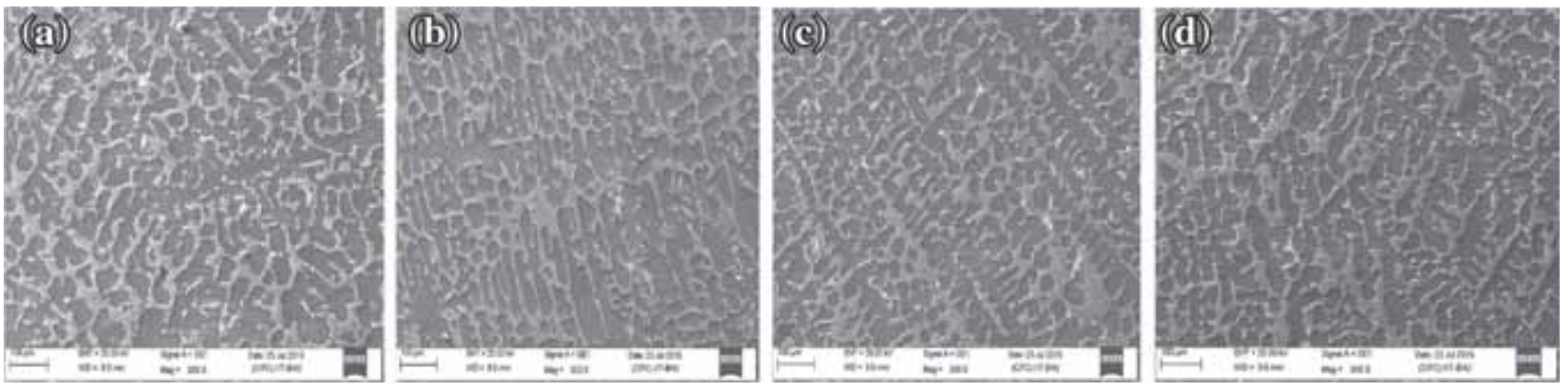

Figure 5. SEM image at amplitude $=5 \mu \mathrm{m}$ and frequency $=100-400 \mathrm{~Hz}$. (a) $100 \mathrm{~Hz}$, (b) $200 \mathrm{~Hz},(\mathbf{c}) 200 \mathrm{~Hz}$, and (d) $400 \mathrm{~Hz}$.

The frequency range of casting was from 100 to $400 \mathrm{~Hz}$ and amplitude was kept constant at $5 \mu \mathrm{m}$. Due to vibration dendrite of aluminum and silicon particle fracture. Due to fracture the size of grains and silicon particle decreased. The average length and width and corresponding area of silicon particles are given in table 2 . The average silicon 

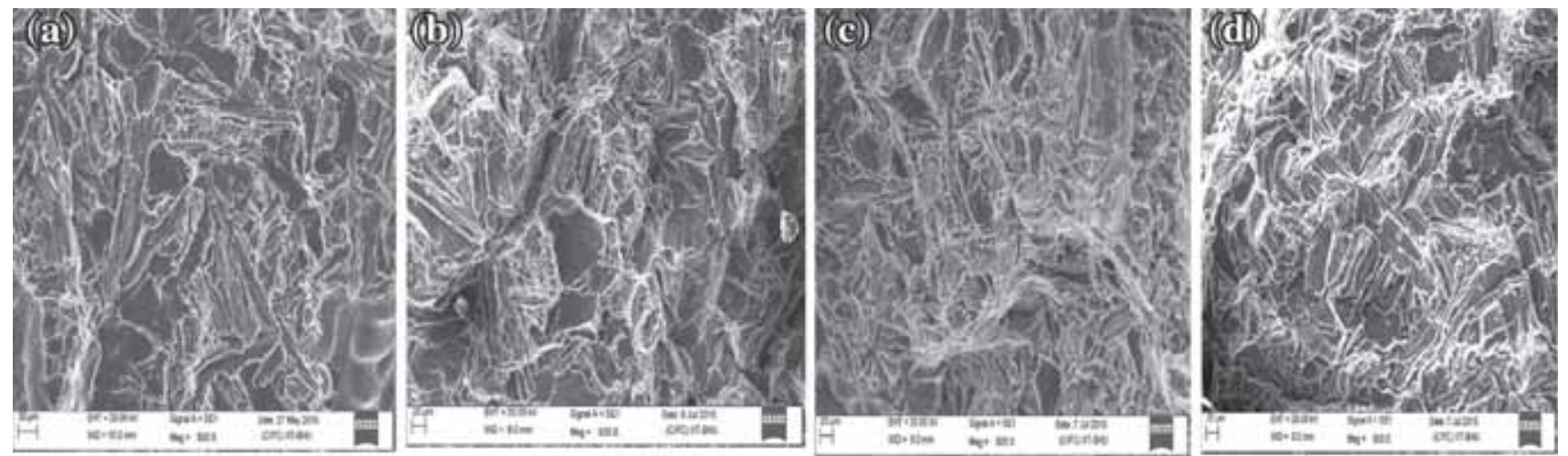

Figure 6. SEM image of tensile fracture at amplitude $=5 \mu \mathrm{m}$ and frequency $=100-400 \mathrm{~Hz}$. (a) $100 \mathrm{~Hz},(\mathbf{b}) 200 \mathrm{~Hz}$, (c) $200 \mathrm{~Hz}$, and (d) $400 \mathrm{~Hz}$.
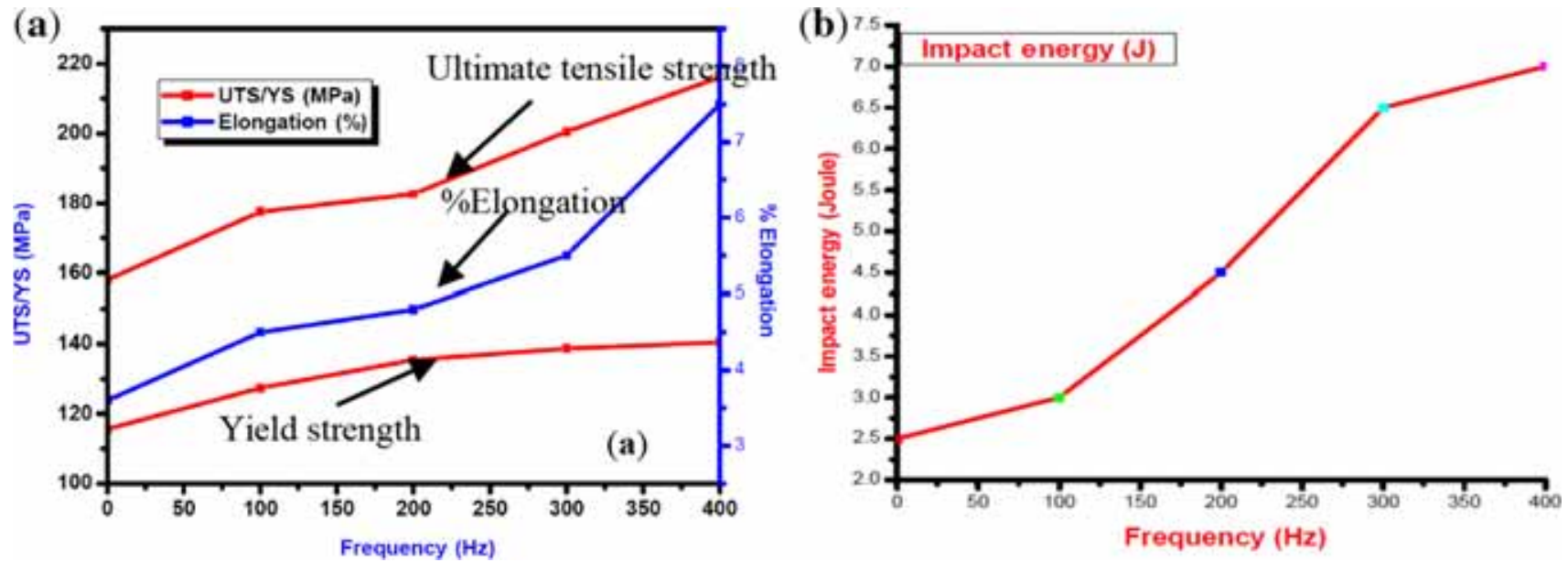

Figure 7. Effect of frequency on ultimate tensile strength, yield strength, \%elongation and impact energy at amplitude $=5 \mu \mathrm{m}$ and under frequency range $=100-400 \mathrm{~Hz}$.

particle area decreased from $1318.47 \mathrm{~m}^{2}$ to $186.18 \mathrm{~m}^{2}$ and corresponding length from $17.45 \mu \mathrm{m}$ to $6.23 \mu \mathrm{m}$ and width from $13.23 \mu \mathrm{m}$ to $3.14 \mu \mathrm{m}$ respectively as shown in table 2 . Table 2 also shows decrease in grain size from $49.19 \mu \mathrm{m}$ to $20.53 \mu \mathrm{m}$, aspect ratio increases from 1.47 to $2.23 \mu \mathrm{m}$ and roundness percentage of silicon particles increase from 33.66 to $71.57 \%$. It is evident that vibration produces fine eutectic of $\mathrm{Al}-\mathrm{Si}$, and the morphology of eutectic silicon changes from acicular to fibrous form.

As per figure 3(a), stationary casting gives coarser grains as compared to vibratory prepared castings figure $5(\mathrm{a}-\mathrm{d})$. The vibration causes grain refinement and non-dendritic structure. The refinement of grain size increases with the increase in frequency of vibration. Figure 5 shows refinement in grains with the increase in vibration frequency. Reduction of grain size is achieved by increasing the nucleation of primary aluminum embryos. This can be done by increasing cooling rate by mechanical vibration to detach dendrite arms.

The fracture surfaces of A356 aluminum alloy are shown in figures 3(c) and 6(a-d) obtained from the stationary and vibratory castings respectively. It showed a clear brittle fracture nature as a transgranular fracture mode due to its coarse microstructure in stationary cast specimen. The fractographs of A356 aluminum alloy obtained with the vibration method exhibited the obvious morphologies of the dimple fracture as an intergranular fracture mode because of a significant improvement in microstructure. Fractrography consists of dimples as well as facets, which indicates that the tensile specimen failed in a quasi-cleavage form (figure 6). The experimental results showed significant improvement in ultimate tensile strength, yield strength, elongation and toughness of castings with mechanical mold vibration during solidification as compared to stationary casting as shown in figure 7.

\section{Conclusions}

The results pertain to the casting of A356 aluminum alloy at different frequencies of vibration. The frequency range of vibration was from $0 \mathrm{~Hz}$ to $400 \mathrm{~Hz}$ at constant amplitude 
of oscillation $5 \mu \mathrm{m}$ during the solidification. On the basis of experimental results following conclusions are drawn.

1. Average area and average length of silicon particle in A356 alloy under vibratory condition decrease with the increase in frequency of vibration of mold. Aspect ratio and roundness of silicon particle increases with increase in frequency of vibration.

2. The acicular eutectic silicon observed in A356 alloy can be improved from acicular to fibrous with the increase in frequency of vibration during the solidification.

3. As per the analysis according to the fracture mode via tensile test, it can be concluded that the fractrography of nonvibrated casting reveals a huge portion of brightly reflecting cleavage facets and some secondary cracks are also visible in fractography micrograph.

4. The SEM image of a tensile fractured surface of vibratory casting reveals that the fracture mode is mixed. It shows dimples with bright cleavage facets in the aluminum matrix. The presence of dimples and facets shows quasi-cleavage fracture.

\section{References}

[1] Hong M G, Xiang J Y and Zhang M 2008 Microstructure characteristics and mechanical properties of rheoformed wrought aluminum alloy $2024 \mathrm{~J}$. Trans. Nonferrous Metals Soc. China 18(3): 555-561

[2] Lin Chong, Wu S S, Zhong G, Wan Li and An Ping 2013 Effect of ultrasonic vibration on Fe-containing intermetallic compounds of hypereutectic Al-Si alloys with high Fe content. Trans. Nonferrous Metals Soc. China 23(5): 1245-1252

[3] Wu S, Xie L, Zhao J and Nakae H 2008 Formation of nondendritic microstructure of semi-solid aluminum alloy under vibration. Scr. Mater. 58(7): 556-559

[4] Wu S S, Zhong G, An Ping, Wan Li and Nakae H 2012 Microstructural characteristics of $\mathrm{Al}-20 \mathrm{Si}-2 \mathrm{Cu}-0.4 \mathrm{Mg}-1 \mathrm{Ni}$ alloy formed by rheo-squeeze casting after ultrasonic vibration treatment. Trans. Nonferrous Metals Soc. China 22(12): 2863-2870

[5] Fan Z 2002 Semisolid metal processing. Int. Mater. Rev. 47(2): 49-85

[6] Abu-Dheir N, Khraisheh M, Saito K and Male A 2005 Silicon morphology modification in the eutectic Al-Si alloy using mechanical mold vibration. Mater. Sci. Eng. A 393(1): $109-117$

[7] Zhang Z, Le Q, Cui J, Cui Z and Hou B 2012 Effect of electromagnetic vibration of mould core region on the solidification structure of magnesium alloy. Proc. Eng. 27: $855-862$

[8] Chirita G, Stefanescu I, Soares D and Silva F S 2009 Influence of vibration on the solidification behaviour and tensile properties of an Al-18wt\%Si alloy. Mater. Des. 30(5): $1575-1580$

[9] Vives C 1996 Crystallization of aluminium alloys in the presence of cavitation phenomena induced by a vibrating electromagnetic pressure. J. Crystal Growth 158(1): 118-127

[10] Wang W, Wang K and Lin X 2009 Crystal nucleation and detachment from a chilling metal surface with vibration. Mater. Chem. Phys. 117(1): 199-203

[11] Kissling R J and Wallace J F 1963 Grain refinement of copper-alloy castings. Foundry 91: 54-57

[12] Piwonka T S 1988 Molding and casting process. Castings ASM handbook, vol. 15, 9th ed., p 656 